\title{
ALTERNATIF MODEL KELEMBAGAAN REFINE: MODEL INOVASI KELEMBAGAAN KLINIK IPTEK MINA BISNIS
}

\author{
An Alternative Institution Model for REFINE: \\ Inovative Institutional Model of the Klinik Iptek Mina Bisnis
}

\author{
Armen Zulham \\ Peneliti dan Koordinator Program KIMBis Tingkat Pusat T.A 2011 - 2013 \\ Balai Besar Penelitian Sosial Ekonomi Kelautan dan Perikanan \\ JI. KS. Tubun Petamburan VI Jakarta 10260 \\ Telp. (021) 53650162, Fax. (021)53650159 \\ Email: keude_bing@yahoo.co.id \\ Diterima 21 Maret 2013 - Disetujui 31 Mei 2013
}

\begin{abstract}
ABSTRAK
Naskah ini, terkait dengan konsepsi Klinik IPTEK Mina Bisnis (KIMBis) dan Research Extension Fisheries Community Network (REFINE). Keduanya merupakan inovasi kelembagaan yang bertujuan menyebarkan IPTEK di daerah pedesaan. Konsepsi KIMBis telah diimplementasikan pada 15 lokasi. Sementara implementasi dari konsepsi REFINE masih dalam wacana. Konsepsi dasar keduanya sangat berbeda tetapi tujuannya hampir sama. Kelembagaan KIMBis dibangun melalui partisipasi berbagai stakeholder dengan pendekatan bottom up. Sementara kelembagaan REFINE dikembangkan dengan membentuk Kelompok Kerja (Pokja) pada tingkat pusat dan daerah, pendekatannya adalah top down. Sumber informasi utama tulisan ini adalah pengamatan lapangan terhadap perilaku berbagai stakeholder, serta laporan 15 lokasi KIMBis dan dokumen REFINE. Hasil pengamatan menunjukkan bahwa KIMBis dapat dimodifikasi sebagai alternatif model kelembagaan REFINE. Modifikasi kelembagaan sebagai penyebar inovasi ini tergantung pada kemauan politik dari perumus kebijakan. Selain itu fleksibilitas lembaga tersebut juga memegang peranan penting dalam menarik pemangku kepentingan berpartisipasi dalam kelembagaan itu. Kelembagaan berbasis masyarakat umumnya lebih mudah diimplementasikan dibandingkan kelembagaan formal dalam bentuk Pokja. Fleksibilitas KIMBis membuat kelembagaan tersebut berperan multi fungsi. Namun untuk memfungsikan KIMBis: sebagai sarana pemberdayaan masyarakat berbasis IPTEK, sarana pengembangan ekonomi masyarakat berbasis IPTEK, sarana kerja sama peneliti, perekayasa dan penyuluh dalam menerapkan dan menyebarkan IPTEK serta memperoleh umpan balik untuk merenovasi IPTEK dan pendekatan yang dilakukan, sebagai tempat kolaborasi dengan lembaga-lembaga yang sudah ada, SKPP, SKPD, Swasta dan LSM dalam mewujudkan kesejahteraan masyarakat, dan sebagai laboratorium lapang aspek sosial ekonomi kelautan dan perikanan dihadapkan pada berbagai kendala. Tingkat partisipasi berbagai pemangku kepentingan terhadap KIMBis sangat bervariasi. Pada masa yang akan datang untuk mengembangkan KIMBis harus mengembangkan sosial kapital dan interkoneksitas, agar partisipasi pemangku kepentingan dapat meningkat.
\end{abstract}

Kata Kunci: sosial kapital, inovasi, pemberdayaan masyarakat, kelautan dan perikanan

\section{ABSTRACT}

This paper is associated with the concept of institutions innovation of the "Klinik IPTEK Mina Bisnis (KIMBis)" and the "Research Extension Fisheries Community Network" (REFINE). The purpose of both the institutions innovation was to spread the technologies at the villages communities. Recently, the KIMBis concept has been implemented at 15 locations, while the REFINE concept still remains a plan. The basic concept of both innovations are very different but the goals almost the same. The KIMBis was built through the participation of a wide range of stakeholders with a bottom up approaching method. Mean while, the REFINE was developed by forming working group (Pokja) at the provincial and the district levels, known a top down approaching method. The main sources of the information for this paper are based on the field observation tows the various stakeholders' behavior, as well as the report of the 15 locations of KIMBis and the REFINE documents. The results show that KIMBis can be modified as the alternative institution for REFINE. This modification depends greatly on the political will of the policy makers. In addition, the flexibility of the institutions is also play an important role in an attracting the 


\begin{abstract}
stakeholders to participate in the institutional program. In the form of working group, the society-based institutions are generally easier to be implemented than the formal institution. The flexibility of KIMBis will build a multi-functioned institution, such as the place for technology-based society empowerment; the place for technology-based rural economic development; and a tool to develop the cooperation among researchers, engineers, and extension officers in applying and spreading technologies as well as obtaining feedbacks to renovate technologies and the approaching methods. The other functions areto facilitate the existing institutions: SKPP,SKPD, private companies and NGO to create public welfare, and as the field laboratory for the socio ecomonic aspects to support the development of marine and fisheries. Recently, the level of participation of the stakeholders involved in the KIMBis activities vary widely. In the future, the development of KIMBis need social capital and interconectivity strategies to boost the stakeholders paticipation on KIMBis program.
\end{abstract}

\title{
Keywords: social capital, innovation, empowerment, marine and fisheries
}

\section{PENDAHULUAN}

Belajar dari pemikiran pencerah inovasi, Joseph Schumpeter (1883 - 1950) tokoh ekonomi kapitalis, dengan dokrin perekonomiankeseimbangan statis, maka untuk mendorong pertumbuhan ekonomi diperlukan inovasi agar keseimbangan statis tersebut menemukan keseimbangan baru setelah terjadi peningkatan output. Bagi Jhingan (1999), inovasi harus dikembangkan terus menerus untuk menjaga momentum pertumbuhan ekonomi. Dengan demikian, inovasi merupakan ciri dari ekonomi kapitalis, dimana inovasi yang dihasilkan oleh inovator harus diimplementasikan oleh entreupreneur untuk menghasilkan barang dan jasa yang baru. Perlu dicatat, inovator atau entreupreneur hanya memiliki daya kreasi yang tinggi, namun dalam konsep Schumpeter inovator itu memiliki kemampuan modal yang terbatas. Oleh sebab itu, untuk mengembangkan inovasi, entrepreneur memerlukan kredit agar inovasi itudapat dikembangkan dalam masyarakat (Syaifullah, 2011).

Kucuran kredit kepada inovator, akan mendorong peningkatan arus uang dalam masyarakat, akibatnya mendorong peningkatan tingkat upah dalam perekonomian. Namun, dengan inovasi itu suplai barang menjadi melimpah di pasaran, dan harga barang merosot. Permasalahan muncul ketika entrepreneur harus membayar kredit yang diterimanya dan membayar upah tenaga kerja. Akibatnya menurut ekonom kapitalis resesi akan terjadi. Namun resesi tersebut dapat dikendalikan dengan berbagai inovasi baru.

Bagi ekonom kapitalis pengikut Schumpeter, siklus inovasi itu dapat mendorong efisiensi dan efektifitas proses produksi, sehingga inovasi diyakini menjadi motor penggerak perekonomian (Romer, 1994). Sebuah inovasi akan berperan dalam perekonomian, jika didukung inovasi kelembagaan yang akomodatif. Dengan pemikiran itu maka, ekonom kapitalis berpandangan jantungnya pertumbuhan ekonomi terletak pada tiga hal, yaitu: inovasi, enterpreuneur dan evolusi kelembagaan (Zuhal, 2012).

Pendapat Schumpeter tersebut sangat bertolak belakang dengan pendapat kelompok ekonom Keynesian yang berkembang saat itu, dimana intervensi pemerintah adalah kunci dari pertumbuhan ekonomi (inovasi). Perseteruan Schumpeter dan kelompok Keynesian ini, diuji ketika ekonomi dunia pada tahun 1970-an dilanda stagflasi (pertumbuhan ekonomi yang lambat, yang diikuti dengan tingkat penggangguran yang tinggi), serta meningkatnya harga-harga secara bersamaan. Keadaan ini tidak mampu diintervensi oleh kebijakan pemerintah (Zuhal, 2013).

Pada saat bersamaan, Romer (1990) terus mengembangkan pemikiran Schumpeter untuk membuktikan inovasi dapat mendorong pertumbuhan ekonomi melalui pemikiranTotal Factor Productivity (TFP) dalam endogeneus growth theory.TPF yang dikembangkan Romer, menurut Aghion and Howit (1997) merupakan faktor yang sangat terkait dengan penguasaan, kemajuan dan implementasi teknologi dalam mengembangkan perekonomian.

Di Indonesia dalam lingkup yang terbatas, implementasi TPF sebagai suatu aksi inovasi berkembang sangat cepat pada dunia usaha. Dengan mengembangkan konsep TPF, maka beberapa grup bisnis di Indonesia dapat bertahan 
saat krisis ekonomi tahun 1998 dan dengan inovasi akhirnya,bisnis mereka berkembang sangat pesat. Informasi tentang inovasi yang dilakukan oleh dunia usaha tersebut dapat dipelajari pada tulisan Luis dan Soesetiyo, (2013) dan (2013a). Pada dunia bisnis di Indonesia yang menerapkan konsep TPF, telah membuat perusahaan itu menjadi pionir untuk menghasilkan barang dan jasa yang belum ada dipasaran, menjadi market leader dari produk dan jasa yang dihasilkan, mendorong menciptakan nilai untuk menghasilkan produk baru setiap saat (Fontana, 2011).

Pada tingkat sektoral pemerintah, inovasi (termasuk Klinik IPTEK Mina Bisnis (KIMBis) dan Research Extension Fisheries Community Network (REFINE)) juga berkembang. Namun perkembangannya tidak secepat pada dunia usaha dan tergantung pada "angin politik". Itulah yang jadi permasalahan pada dalam tulisan ini. Tujuan dari tulisan ini adalah untuk mempelajari berbagai kendala dalam pengembangan KIMBis dan implementasi REFINE.

\section{METODOLOGI}

Naskah ini di susun dengan mengamati perkembangan kelembagaan KIMBis pada berbagai lokasi. Untuk melengkapi pengamatan tersebut, tulisan ini memanfaatkan laporan pelaksanaan kegiatan pada setiap lokasi KIMBis sampai dengan tahun 2012 serta berbagai tulisan ilmiah yang terkait dengan pemberdayaan masyarakat.

Informasi tentang REFINE dipelajari dari dokumen RIFINE Balitbang Kelautan dan Perikanan, yang disusun oleh tim pakar. Analisis data dan informasi menggunakan pendekatan deskriptif kualitatif.

\section{BELAJAR DARI INOVASI TEKNOLOGI LITBANG PERTANIAN}

Pada Sektor Pertanian misalnya, mengawali era green revolution inovasi pertanian dilakukan oleh tim Institut Pertanian Bogor di Karawangpada tahun 1963, melalui program Swa Sembada Bahan Makanan (SSBM). Inovasi ini memperkenalkan teknologi agronomi baru dan penggunaan mekanisasi pertanian (traktor) dalam peningkatan produksi padi (Tjondronegoro, 2011). Selanjutnya program SSBM dilanjutkan pemerintah melalui program Bimas pada tahun 1970-an dalam bentuk paket inovasi modernisasi pertanian. Inovasi ini tercatat dalam berbagai dokumen badan internasional telah berhasil mewujudkan swasembada beras di Indonesia pada tahun 1984

Keberhasilan program Bimas menurut Subejo (2011), karena penyuluh pertanian ditempatkan pada posisi yang sangat penting untuk mendorong teknologi hasil penelitian pertanian di adopsi petani. Penyuluh pertanian diberi kepercayaan untuk memberi bimbingan teknis "panca usaha tani" yang dihasilkan peneliti. Peran penyuluh pertanian mendapat dukungan politik, finansial dan fasilitas yang memadai, sehingga mereka dapat menjalankan fungsinya dengan lancar.

Setelah swasembada beras tercapai kebijakan pembangunan pertanian dalam berbagai dokumen dilanjutkan ke arah pembangunan industri berbasis pertanian. Industri yang dikembangkan menurut Subejo (2011), tidak berkaitan sama sekali dengan pertanian. Akibatnya fungsi penyuluh pertanian semakin kurang optimal.

Ditengah stagnasi adopsi teknologi pertanian, pada tahun 1990-an dalam Badan penelitian dan pengembangan Pertanian dibentukBalai Pengkajian Teknologi Pertanian (BPTP), yang mengabungkan unit kerja kebun percobaan, balai atau sub balai penelitian pertanian yang ada di daerah dengan unit kerja Balai Informasi Pertanian pada setiap provinsi. Pembentukan BPTP ini dilakukan setelah ada kajian mendalam tentang Research Extention Linkages (Qomar, 2003). Tujuannya adalah untuk meningkatkan peran peneliti pertanian dan penyuluh pertanian dalam penyebaran hasil litbang pertanian pada masyarakat. Kehadiaran BPTP, diharapkan mampu mempercepat adopsi teknologi hasil penelitian pertanian kepada masyarakat (Agbamu, 2000).

Selama keberadaan BPTP berbagai inovasi telah diperkenalkan, dengan melibatkan peneliti-penyuluh, seperti Program Sistim Usaha Tani Padi (SUTPA) yang memperkenalkan teknologi alat tanam benih langsung (Atabela) dan berbagai variestas padi baru untuk meningkatkan produksi padi, Sistim Usaha Pertanian (SUP) untuk mendorong peningkatan produksi berbagai komoditas pertanian. Pada program tersebut menurut Haryono (2013) diperkenalkan inovasi teknologi tunggal (misalnya pengendalian Organisme Pengganggu Tanaman, pengaturan populasi tanaman, dan lainnya) dan inovasi teknologi kombinasi yang disebut PTT (Pengelolaan Tanaman dan Sumberdaya Terpadu). 
Pada tahun 2005 diperkenalkan Prima Tani (Program Rintisan dan Akselerasi Pemasyarakatan Inovasi Teknologi Pertanian), program ini berakhir pada tahun 2010. Prima Tani dilakukan pada satu hamparan kawasan produksi pertanian dengan tujuan agar usaha tersebut economic of scale, dan dalam kawasan tersebut terdapat laboratorium lapangan yang dapat menjadi rujukan petani lain.

Secara operasional Prima Tani dilaksanakan dengan mengembangkan inovasi kelembagaan, pada tingkat Badan Litbang Pertanian dibentuk tim pakar Prima Tani, dan setiap lokasi Prima Tani ditunjuk unit kerja eselon 2 lingkup Badan Litbang KP sebagai penyelia. Penanggung jawab Prima Tani pada setiap provinsi adalah Kepala BPTP, dan pada setiap lokasi Prima Tani dan Laboratorium Lapangditunjuk seorang manajer. Dengan struktur yang demikian maka seluruh eselon 2 lingkup Badan Litbang Pertanian berperan dalam kegiatan Prima Tani.

Prima Tani mencoba menerapkan berbagai teknologi hasil penelitian tentang tanaman pangan, perkebunan, peternakan, hortikultura, produk olahan maupun pengelolaan lahan pertanian kepada masyarakat. Koordinasi dan kerjasama penyuluh - peneliti - pemda menjadi kata kunci yang harus berhasil dibangun oleh Kepala BPTP untuk mensukseskan program ini. Selama 5 tahun pelaksanaan, program ini telah memberi lesson learn yang cukup signifikan terhadap proses penyebaran teknologi pertanian dalam mendukung program pembangunan pertanian. Setelah itu, dalam Badan Litbang Pertanian berkembang berbagai inovasi seperti perbenihan dengan sistim waralaba, unit komersialisasi hasil penelitian dan lain sebagainya.

\section{KONSEPSI REFINE}

Sebelum KIMBis terbentuk selama tahun 2010 sampai 2011 di Badan Litbang Kelautan dan Perikanan, sering terjadi diskusi tentang cara adopsi dan diseminasi/difusi teknologi hasil penelitian dan pengembangan kelautan dan perikanan. Diskusi diarahkan untuk merumuskan konsep peningkatan partisipasi para pemangku kepentingan bidang KP melalui REFINE dalam penelitian pengembangan teknologi hasil penelitian KP yang jenerik (teknologi jenerik/ generic technology) menjadi teknologi adaptif

lokasi (TAL), agar sesuai dengan lokasi dan lingkungan tempat adopsi dan diseminasi/difusi tersebut.
Upaya kerjasama antara penelitian, penyuluhan dan masyarakat KP melalui REFINE telah banyak dirintis, melalui kerjasama dalam pelaksanaan kegiatan, tetapi kerjasama tersebut belum melembaga sehingga usia kerjasama tersebut tidaklah lama.

Pada dokumen Badan Penelitian dan Pengembangan Kelautan dan Perikanan (Badan Litbang KP), REFINE didefinisikan sebagai: suatu sistem penyediaan teknologi KP hasil penelitian dan pengembangan, yang diawali dan diakhiri bersama masyarakat KP sehingga teknologi yang tersedia sesuai dengan kebutuhan, dengan memperhatikan faktor-faktor ekologi manusia dan ekologi biofisik untuk meningkatkan produksi, produktivitas, nilai tambah dan daya saing serta meningkatkan kesejahteraan masyarakat perikanan (Anonymous, 2011).

Kegiatan penelitian dan pengembangan dalam REFINE ialah kegiatan Badan Litbang KP. Kegiatan penelitian pengembangan dalam Badan Litbang KP akan disinergikan dengan kegiatan serupa dari lembaga lain seperti LIPI, BPPT, Perguruan Tinggi, Balitbangda, dan sebagainya.

Berdasarkan uraian diatas, maka REFINE adalah suatu sistem yang memadukan kekuatankekuatan yang ada pada penelitian, penyuluhan dan masyarakat KP serta pemangku kepentingan lainnya, untuk melaksanakan penelitian dan pengembangan teknologi partisipatif, melalui kerjasama yang saling melengkapi, saling bersinergi dan membangun kebersamaan untuk mewujudkan visi dan misi pembangunan kelautan dan perikanan.

\section{KIMBis SEBAGAI PERCONTOHAN REFINE}

Bercermin pada Prima Tani, maka BBPSEKP mencoba mengimplementasikan konsepsi REFINE, dengan mendorong partisipasi peneliti, penyuluh, perekayasa dan berbagai pemangku kepentingan dalam masyarakat untuk menyebarkan IPTEK hasil litbang kelautan dan perikanan melalui kelembagaan KIMBis dalam format yang lebih luas.

Dilapangan KIMBis dikembangkan sebagai suatu kegiatan penelitian aksi, Balai Besar Penelitian Sosial Ekonomi Kelautan dan Perikanan (BBPSEKP) yang antara lain bertujuan menyebarkan keberhasilan teknologi hasil introduksi dari program IPTEKMAS unggulan Balitbang Kelautan dan Perikanan, program 
unggulan dari sumber lain yang dapat dipertanggung jawabkan untuk mendukung program Kementerian Kelautan dan Perikanan. Inovasi yang dikembangkan ini selaras dengan konsepsi TFPRomer yang diuraikan diatas.

Dengan keterbatasan wewenang dan tupoksi dari BBPSEKP, maka KIMBis dibangun sebagai sebuah kelembagaan masyarakat kelautan dan perikanan yang dibentuk oleh berbagai pemangku kepentingan dengan prinsip partisipatif untuk memanfaatkan berbagai peluang dalam rangka mewujudkan kesejahteraan masyarakat (Zulham, 2012).

Batasan ini memberi makna bahwa kelembagaan KIMBis harus dikembangkan melalui konsep modal sosial (social capital). Perlu dicatat bahwa modal sosial adalah kemampuan pengurus KIMBis membangun jaringan kerjasama dan memanfaatkan potensi pada berbagai pemangku kepentingan untuk mempercepat terwujudnya kesejahteraan masyarakat dengan memanfaatkan IPTEK hasil litbang. Potensi pada berbagai pemangku kepentingan sangat banyak pada lingkungan KIMBis, seperti donasi, teknologi serta kepakaran.

Tesis sentral dari modal sosial yang dianut KIMBis, meminjam konsep Field (2003). Namun, sayangnya konsepsi tersebut tidak diekspolrasi dengan baik oleh pengurus KIMBis, dan yang dieksplorasi adalah kegiatan fisik pelatihan dan sosialisasi teknologi yang dilakukan pada paket kegiatan KIMBis. Tesis sentral tersebut pada dasarnya upaya membangun dan mengembangkan hubungan dengan berbagai pemangku kepentingan dan menjaga agar hubungan tersebut dapat berlangsung sepanjang waktu untuk mencapai tujuan yang direncanakan di dalam KIMBis.

Oleh sebab itu, KIMBis berupaya membangun relasi dengan satuan kerja lingkup Balitbang Kelautan dan Perikanan sebagai pemilik teknologi dan sumber teknologi lain yang dapat dipertanggung jawabkan. Satker litbang ini juga merupakan sumber kepakaran. Penyuluh perikanan yang terdapat di daerah karena memahami kondisi lapangan. Satuan Kerja Pemerintah Daerah (SKPD), karena mempunyai kegiatankegiatan pemberdayaan masyarakat dan program perbantuan, Satuan Kerja Pemerintah Pusat (SKPP) yang merancang berbagai program pembangunan masyarakat. SKPD dan SKPP tersebut merupakan sumber kegiatan dan donasi.Perguruan Tinggi yang mempunyai teknologi dan mahasiswa sebagai pendamping program pembangunan, Lembaga Swadaya Masyarakat (LSM) danYayasan yang memiliki program pemberdayaan masyarakat serta perusahaan swasta dan BUMN yang mempunyai program Corporate Social Responsibility (CSR). Relasi tersebut dibangun untuk mendorong agar kegiatan yang terdapat pada para pemangku kepentingan dapat dilaksanakan pada kawasan KIMBis.

Bagi KIMBis pengembangan modal sosial, itu dibangun melalui struktur organisasi KIMBis yang akomodatif. Dalam struktur organisasi tersebut terdapat unsur SKPD, tokoh masyarakat dan penyuluh untuk mempercepat proses pengembangan jaringan kerja sama.

Struktur organisasi KIMBis pada tingkat BBPSEKP dibentuk sekretariat KIMBis dan Koordinator KIMBis. Pada lokasi KIMBis dibentuk Tim pelaksana KIMBis pusat dan pengurus KIMBis lokasi. Tim pelaksana KIMBis pusat terdiri dari peneliti BBPSEKP dan beberapa peneliti dari Satuan Kerja (Satker) Lingkup Balitbang KP. Pengurus KIMBis di lokasi ditentukan secara partisipatif dengan mengikutsertakan berbagai pemangku kepentingan. Posisi penting dari pengurus lokasi biasanya diisi oleh penyuluh perikanan seperti: Manajer, Liasson Officer (LO), dan tergantung dari jumlah penyuluh perikanan (PNS atau Penyuluh Perikanan Tenaga Kontrak) yang tersedia pada kawasan KIMBis. Posisi lain dari pengurus KIMBis diisi oleh kader pembangunan desa.

Dengan demikian, jika kelembagaan KIMBis dijadikan sebagai salah satu kebijakan untuk mendorong penyebaran IImu Pengetahuan dan Teknologi (IPTEK) hasil introduksi pada Program IImu Pengetahuan dan Teknologi untuk Masyarakat (IPTEKMAS) maka pada setiap lokasi KIMBis harus ditunjuk eselon 2 lingkup Balitbang KP sebagai penyelia dari program KIMBis. Hal tersebut tidak dapat dilakukan kecuali posisi KIMBis ditempatkan dalam program strategis Balitbang KP.

Perlu dicatat, anggaran pelaksanan KIMBis pada BBPSEKP sangat terbatas, namun potensi donasi untuk mendukung inovasi teknologi menjadi bagian dari inovasi kebijakan maupun kegiatan pemberdayaan masyarakat pada berbagai pemangku kepentingan sangat besar. Potensi itu akan dapat diwujudkan jika tim pelaksana KIMBis pusat berhasil membangun modal sosial seperti yang dimaksudkan diatas. Oleh sebab itu, dengan SK. Ka. Balitbang KP No. 12.1/BALITBANGKP/ 
RS.210/I/2012 tentang pembentukan KIMBis, maka produk hukum tersebut merupakan modal untuk membangun interkoneksitas dalam lingkup satker litbang KP.

Selain itu untuk membangun modal sosial pada kawasan KIMBis dilakukan pendekatan formal dan non formal. Pendekatan formal dilakukan dengan penandatangan Memorandum of Understanding (MoU) antara eselon 1 Balitbang KP dengan Bupati atau Walikota dan Perjanjian Kerja Sama (PKS) antara Kepala BBPSEKP dengan Kepala SKPD di Kabupaten atau Kota terkait. Pendekatan non formal dilakukan dengan memanfaatkan tokoh-tokoh masyarakat dan kader pembangunan desa untuk memanfaatkan semua potensi yang ada. Sehingga akan dapat membantu percepatan pencapaian tujuan pembangunan Kelautan dan Perikanan.

Dalam pelaksanaan kegiatan pada satu kawasan, KIMBis tidak membentuk kelompok baru dalam masyarakat, KIMBis memanfaatkan kelompok yang telah dibentuk oleh Program Usaha Mina Pedesaan, Program Usaha Garam Rakyat, Program Desa Pesisir Tangguh dan IPTEKMAS. KIMBis memanfaatkan kelompok yang ada dengan memperkuat soft skill mereka, untuk mengakses berbagai sumber informasi dan teknologi serta permodalan. Dengan demikian akan muncul kemandirian dalam kehidupan ekonomi masyarakat.Langkah tersebut dilakukan, karena KIMBis berupaya menempatkan masyarakat sebagai subjek pembangunan, dan memotivasi mereka bertanggung jawab terhadap berbagai program yang terdapat dalam lingkungan mereka, sehingga bantuan pemerintah yang telah ada dalam masyarakat dirancang sebagai pemicu kreativitas ekonomi agar usaha mereka menjadi berkembang.

Dengan demikian, KIMBis dapat dikatagorikan sebagai, kelembagaan bottom - up ${ }^{1}$ yang bersifat partisipatif menempatkan masyarakat sebagai subjek pembangunan.Dengan katagori itu, maka kelembagaan KIMBis punya peluang untuk memanfaatkan berbagai potensi pembangunan untuk mewujudkan kesejahteraan masyarakat. Potensi itu, mencakup kegiatan yang terdapat pada berbagai Satuan Kerja Pemerintah Pusat (SKPP), Satuan Kerja Pemerintah Daerah (SKPD) serta swasta dan Badan Usaha Milik Negara (BUMN); teknologi tepat guna yang dihasilkan oleh lembaga penelitian pemerintah atau perguruan tinggi; bahkan bantuan konsultasi dan pendampingan yang disediakan oleh peneliti, penyuluh.

Jika demikian halnya, maka dalam jangka panjang lembaga KIMBis itu, dapat dimanfaatkan oleh berbagai pemangku kepentingan, menjadi agen pembangunan untuk berpartisipasi melaksanakan berbagai program yang dirancang pada desa-desa yang perekonomiannya tergantung pada sumberdaya kelautan dan perikanan untuk pengentasan kemiskinan.

Namun dalam jangka pendek kelembagaan KIMBis dapat dijadikan sebagai pusat penyebaran inovasi teknologi pedesaan, karena lembaga KIMBis dapat dijadikan sebagai tempat untuk memotivasi masyarakat memanfaatkan IPTEK (terutama hasil penelitian). Kegiatan tersebut akan menghasilkan enterpreneur di pedesaan yang dapat dijadikan master of trainer di pedesaan dalam pengembangan perekonomian wilayah. Jika demikian halnya, maka KIMBis itu dapat dikatakan sebagai lembaga pemberdayaan masyarakat dan penyebaran IPTEK pada masyarakat pedesaan.

a. Membangun dan memperkuat relasi quasy integrasi ${ }^{2}$ antar pemangku kepentingan: masyarakat, SKPP, SKPD dan pengusaha. Dengan demikian, KIMBis tidak soliter dan akan memperkuat hubungan horizontal dan vertikal seluruh pemangku kepentingan dalam mensukseskan pelaksanaan program dan tujuan pembangunan nasional.

b. Meningkatkan social capital masyarakat. Peningkatan tersebut difasilitasi oleh peneliti, penyuluh dan pengurus KIMBis melalui pendampingan dan pengawalan teknologi. Tujuannya adalah untuk meningkatkan kemampuan manajerial masyarakat dalam mengoptimalkan pemanfaatan sumberdaya alam yang tersedia serta meraih berbagai peluang yang ada pada berbagai pemangku kepentingan.

c. Mengoptimalkan pemanfaatkan bantuan (peralatan dan permodalan) yang telah dibagikan kepada masyarakat oleh berbagai

\footnotetext{
${ }^{1}$ Mengajak pemangku kepentingan untuk mengorganisasikan diri agar dapat memobilisasi berbagai kesempatan dan peluang yang ada disekitarnya agar mandiri. Aturan organisasi itu disusun oleh masyarakat sendiri

${ }^{2}$ Quasi integrasi itu dapat diartikan sebagai relasi simbiosis mutualisme. Memanfaatkan kelebihan dari masing-masing pemangku kepentingan. Lembaga penelitian dan Universitas memiliki tenaga ahli dan teknologi, sedangkan donasi tersedia pada SKPP, SKPD dan swasta
} 
SKPP dan SKPD, serta swasta. Oleh sebab itu, KIMBis merupakan wadah kerjasama antar pemangku kepentingan, untuk mencapai tujuan yang direncanakan.

d. Membangun struktur organisasi dan koordinasi dalam masyarakat, dengan atau tanpa pemerintah dalam rangka membangun kontruksisosial ${ }^{3}$ untuk mengembangkan

perekonomian mereka secara mandiri.

Peran KIMBis yang demikian diharapkan mampu menumbuhkan kewirausahaan dalam masyarakat, sehingga berperan membuka lapangan kerja dan menciptakan sumber pendapatan. Dengan demikian kelembagaan ini bukan hanya dimanfaatkan sebagai lembaga yang dapat menyebarkan IPTEK namun bermanfaat untuk mendukung program dari berbagai pemangku kepentingan.

\section{IMPLEMENTASI KIMBis di LAPANGAN}

Gambaran utuh REFINE dilapangan belum terbentuk. Namun, jika KIMBis dapat dianggap sebagai sebagai percobaan awal dari REFINE, maka KIMBis itu dapat katagorikan sebagai sebuah kelembagaan multi fungsi. Paling sedikit terdapat 5 fungsi KIMBis, yaitu :

a. Sebagai sarana pemberdayaan masyarakat berbasis IPTEK.

b. Sebagai sarana pengembangan ekonomi masyarakat berbasis IPTEK.

c. Sebagai sarana kerja sama peneliti, perekayasa dan penyuluh dalam menerapkan dan menyebarkan IPTEK serta memperoleh umpan balik untuk merenovasi IPTEK dan pendekatan yang dilakukan.

d. Sebagai tempat kolaborasi dengan lembaga-lembaga yang sudah ada, SKPP, SKPD, Swasta dan LSM dalam rangka mewujudkan kesejahteraan masyarakat.

e. Sebagai laboratorium lapangan untuk memperoleh data aspek sosial ekonomi kelautan dan perikanan dalam rangka mendukung pembangunan kelautan dan perikanan.

Untuk melaksanakan fungsi yang disebutkan diatas, maka dilaksanakan berbagai kegiatan.

Tabel 1. Deskripsi Kegiatan KIMBis Menurut Fungsinya.

Table 1. The KIMBis Activities Description Based on Its Function.

\begin{tabular}{|c|c|c|}
\hline No & $\begin{array}{l}\text { Fungsi KIMBis/ } \\
\text { KIMBis Functions }\end{array}$ & $\begin{array}{l}\text { Deskripsi Kegiatan/ } \\
\text { Activities Description }\end{array}$ \\
\hline 1. & $\begin{array}{l}\text { Pemberdayaan Masyarakat berbasis } \\
\text { IPTEK (IPTEK Based for Society } \\
\text { Empowerment) }\end{array}$ & $\begin{array}{l}\text { Membangun kemampuan masyarakat untuk } \\
\text { mengakses sumber teknologi, layanan kesehatan, layanan permodalan dan } \\
\text { peluang pasar./Build the human society capability to accces the source of } \\
\text { technology, healt services, financial srvices and market opportunity. }\end{array}$ \\
\hline 2. & $\begin{array}{l}\text { Pengembangan Ekonomi Masyarakat } \\
\text { berbasis IPTEK (IPTEK Based for } \\
\text { Society Economic Development) }\end{array}$ & $\begin{array}{l}\text { Membangun mitra usaha rumah tangga dan skala mikro, inisiasi pengembangan } \\
\text { sumber permodalan, pengembangan produk dan akses pasar./Develophousehold } \\
\text { and micro business partners, initiation to organize the finacial development, } \\
\text { promote product and market development. }\end{array}$ \\
\hline 3. & $\begin{array}{l}\text { Wadah kerjasama Peneliti - Penyuluh } \\
\text { dan perekayasa (Collaboration area's } \\
\text { for researchers - extention workers } \\
\text { and research engineers) }\end{array}$ & $\begin{array}{l}\text { Mengintoduksikan teknologi tepat guna hasil introduksi pada program IPTEKMAS } \\
\text { dan teknologi tepat guna lain sesuai dengan kebutuhan masyarakat, sehingga } \\
\text { akan diperoleh umpan balik terhadap teknologi tersebut. /Introduce efectiveness } \\
\text { technlogy from the result of introduction to IPTEKMAS programs and the others } \\
\text { efectiveness technology that appropriate with human society needs, and have the } \\
\text { feed back for the technology. }\end{array}$ \\
\hline 4. & $\begin{array}{l}\text { Sarana kerja sama SKPP - SKPD - } \\
\text { dan Kelembagaan lainnya (the area' } \\
\text { collaboration places of SKPP - SKPD } \\
\text { and otherintitutions) }\end{array}$ & $\begin{array}{l}\text { Memperkuat kerja sama dan melaksanakan kegiatan untuk mendorong } \\
\text { agar inovasi teknologi menjadi bagian penting dari inovasi kebijakan untuk } \\
\text { mendukung target pembangunan. ISupported colaboaration and carry out } \\
\text { the activity to encourage innovation of technology became important part from } \\
\text { policy innovation for support development targets. }\end{array}$ \\
\hline 5. & $\begin{array}{l}\text { Laboratorium data aspek Sosial } \\
\text { Ekonomi Kelautan dan Perikanan. } \\
\text { (Socio economic data laboratory for } \\
\text { marine and fisheries) }\end{array}$ & $\begin{array}{l}\text { Pengamatan aspek sosial ekonomi dan perilaku seluruh pemangku kepentingan } \\
\text { terkait dengan } 5 \text { fungsi KIMBis, monitoring dan evaluasi aspek sosial ekonomi } \\
\text { dari inovasi teknologi dan inovasi kebijakan agar dapat dijadikan bahan untuk } \\
\text { berbagai kebijakan KP. /Observation socio economic aspect and the behavior } \\
\text { all of stakeholders that associated with } 5 \text { fuctions of KIMbis, socio economic } \\
\text { monitoring and evaluation from innovation of technology and innovation of policy } \\
\text { so can be raw materials for marine and fisheries policy. }\end{array}$ \\
\hline
\end{tabular}

${ }^{3}$ Kontruksi sosial adalah membangun kemampuan untuk mengakses: informasi, sumber IPTEK dan berbagai potensi pembangunan. 
Karakteristik kegiatan yang dilakukan dalam kelembagaan KIMBis adalah seperti pada Tabel 1.

Dengan fungsi seperti pada Tabel 1, maka KIMBis pada 15 lokasi yang tersebar pada berbagai wilayah di Indonesia dapat dikatagorikan sebagai kelembagaan masyarakat yang multi fungsi dan berperan mendorong kemandirian perekonomian masyarakat agar dapat berkembang.

Fungsi KIMBis yang unik seperti pada tabel diatas, mendorong beragam tanggapan dari pemangku kepentingan berpartisipasi di dalam
KIMBis. Padahal partisipasi pemangku kepentingan tersebut sangat diperlukan terkait dengan upaya mewujudkan kesejahteraan masyarakat.

Tabel 2, memberi gambaran tingkat partisipasi berbagai pemangku kepentingan terhadap kegiatan di dalam KIMBis. Informasi dari tabel tersebut menunjukkan terdapat berbagai kendala yang dihadapi kelembagaan KIMBis dalam melaksanakan lima fungsi KIMBis.

Peran KIMBis dalam penyebaran IPTEK hasil litbang sangat efektif, namun kendalanya adalah

Tabel 2. Tingkat Partisipasi Pemangku Kepentingan pada KIMBis.

Table 2. The Rate of Participaton Stakeholdrers in KIMBis.

\begin{tabular}{|c|c|c|c|c|}
\hline No & $\begin{array}{l}\text { Pemangku } \\
\text { Kepentingan/ } \\
\text { Stakeholders }\end{array}$ & $\begin{array}{l}\text { Tingkat Partisipasi } \\
\text { saat ini a) / } \\
\text { The Current Rate of } \\
\text { Participation }\end{array}$ & $\begin{array}{l}\text { Tingkat Partisipasi } \\
\text { yang diharapkana) / } \\
\text { The Expected Rate } \\
\text { of Participation }\end{array}$ & $\begin{array}{l}\text { Diskripsi / } \\
\text { Description }\end{array}$ \\
\hline 1. & $\begin{array}{l}\text { Satker Litbang } \\
\mathrm{KP} / \text { Reseach } \\
\text { and Development } \\
\text { Unit of Marine } \\
\text { and Fisheries }\end{array}$ & $\begin{array}{l}\text { Partisipasi pasif/ } \\
\text { Pasive Participations }\end{array}$ & $\begin{array}{l}\text { Partisipasi interaktif } \\
\text { /Interactive } \\
\text { Participations }\end{array}$ & $\begin{array}{l}\text { Satker litbang pemilik teknologi } \\
\text { diharapkan berperan aktif dalam } \\
\text { implementasi teknologi yang inovatif } \\
\text { dan adaptif dalam skala luas melalui } \\
\text { KIMBis. /Reseach and Development } \\
\text { Unit that has technology plays an } \\
\text { active role in the implementation } \\
\text { innovative and adaptive technology } \\
\text { in the wide scale }\end{array}$ \\
\hline
\end{tabular}

2. Satuan Kerja Partisipasi pasif /

Pemerintah Pusat Pasive partcipations (SKPP) /Central
Goverment unit
Partisipasi mandiri

IIndependent participations
SKPP diharapkan dapat mengambil keputusan memanfaatkan KIMBis menjadi bagian dalam membantu pencapaian program. /Central goverment unit is excpected can take decisions herness of KIMBis to be part that can help programs achievment

\begin{tabular}{|c|c|c|c|c|}
\hline 3. & $\begin{array}{l}\text { Satuan Kerja } \\
\text { Pemerintah } \\
\text { Daerah (SKPD)/ } \\
\text { Regional } \\
\text { Goverment } \\
\text { working Unit }\end{array}$ & $\begin{array}{l}\text { Partisipasi konsultatif } \\
\text { /Consultative } \\
\text { participations }\end{array}$ & $\begin{array}{l}\text { Partisipasi } \\
\text { fungsional /Fuctional } \\
\text { participations }\end{array}$ & $\begin{array}{l}\text { Peran fungsional SKPD secara } \\
\text { bertahap dapat menunjukkan } \\
\text { kemandiriannya dalam mendukung } \\
\text { kegiatan di dalam KIMBis. /The role } \\
\text { of fuctional SKPD gradually can show } \\
\text { his independence in support in the } \\
\text { KIMBis activities }\end{array}$ \\
\hline 4. & $\begin{array}{l}\text { LSM /Non } \\
\text { Goverment } \\
\text { Organizations }\end{array}$ & $\begin{array}{l}\text { Partisipasi konsultatif } \\
\text { /Consultative } \\
\text { participations }\end{array}$ & $\begin{array}{l}\text { Partisipasi mandiri/ } \\
\text { Independent } \\
\text { participations }\end{array}$ & $\begin{array}{l}\text { LSM diharapkan dapat membuat } \\
\text { keputusanmenjadikanKIMBis } \\
\text { menjadi bagian program kegiatannya. } \\
\text { INGOis expected can make a } \\
\text { decisions that can make KIMBis to be } \\
\text { part of hisactivity programs }\end{array}$ \\
\hline 5. & $\begin{array}{l}\text { Masyarakat / } \\
\text { Society }\end{array}$ & $\begin{array}{l}\text { Partisipasi interaktif/ } \\
\text { Interactive } \\
\text { participations }\end{array}$ & $\begin{array}{l}\text { Partisipasi mandiri } \\
\text { /Independet } \\
\text { participations }\end{array}$ & 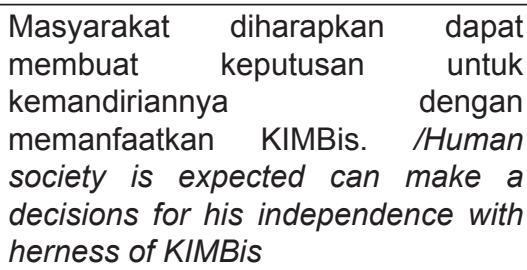 \\
\hline
\end{tabular}

Keterangan: a) Batasan partisipasi menurut Pretty (1999)./ Remark: Rate of participation based on Pretty (1999). 
tingkat partisipasi dari pemangku kepentingan yang belum berperan seperti yang diharapkan. Gambaran singkat tentang partisipasi pemangku kepentingan tersebut adalah seperti pada Tabel 2.

Tingkat partisipasi Satker Litbang KP, dapat dikatagorikan pada tingkat partisipasi pasif. Tingkat partisipasi ini merupakan tingkat partisipasi yang paling lemah. Sebagian besar Satker Litbang KP melihat kelembagaan KIMBis sebagai kelembagaan yang menjadi saingan dari program IPTEKMAS yang sedang dilaksanakannya. Kegiatan-kegiatan yang dilakukan di dalam KIMBis dianggap menyalahi aturan yang berlaku terutama kegiatan yang terkait dengan introduksi teknologi. Partisipasi Satker Litbang yang diharapkan adalah partisipasi interaktif, Satker Litbang KP diharapkan mampu menganalisis secara jernih tentang kerugian dan keuntungan berpartisipasi di dalam KIMBis. Analisis dapat dilakukan setelah melalui tahapan dialogis antara Satker Litbang $\mathrm{KP}$ dengan pengurus $\mathrm{KIMBis,} \mathrm{dan} \mathrm{setelah} \mathrm{ikut}$ serta pada beberapa kegiatan KIMBIs. Analisis ini perlu dilakukan untuk mengambil keputusan terkait dengan peran output dan dampak dari partisipasi mereka di dalam KIMBis.

Tingkat partisipasi SKPP sama dengan tingkat partisipasi Satker Litbang. SKPP menganggap kegiatan yang dilakukan oleh KIMBis merupakan kegiatan aksi yang bukan menjadi tupoksinya. Hal ini disebabkan karena SKPP melihat KIMBis identik dengan Satuan Kerja Penelitian yang tidak punya kapasitas untuk mengimplementasikan program. Partisipasi SKPP yang diharapkan adalah partisipasi mandiri, dimana SKPP dapat melakukan mobilisasi sumberdaya dan keputusan yang ada padanya agar dapat memanfaatkan kelembagaan KIMBis untuk melaksanakan program yang direncanakannya. Dengan wewenang yang ada, maka SKPP dapat membuat keputusan, perjanjian dan kegiatan dengan berbagai pihak untuk mendorong investasi, teknologi dan pakar untuk mendukung kegiatannya dengan memanfaatkan kelembagaan KIMBis agar pelaksanaan programnya pada kelompok sasaran dapat mencapai program seperti yang diharapkan.

Pada sisi lain tingkat partisipasi SKPD dapat dikatagorikan sebagai tingkat partisipasi konsultatif. SKPD cenderung bersikap konsultatif dalam memutuskan keikutsertaan mereka di dalam kelembagaan KIMBis.Konsultasi dilakukan terkait dengan keuntungan dan kerugian dari partisipasi mereka bergabung dengan KIMBis, terutama yang berhubungan dengan kontribusi dalam kegiatan yang dilakukan, dan kewajiban jangka panjang terhadap kelembagaan KIMBis. Dalam pemikiran para pemangku kepentingan tersebut, mereka mengharapkan KIMBis membawa proyek yang menguntungkan mereka. Padahal KIMBis hanya membawa teknologi dengan donasi dari para pemangku kepentingan. Partisipasi SKPD yang diharapkan adalah partisipasi fungsional, dimana SKPD yang ada ikut berperan menjadi pendorong agar SKPD-SKPD lain ikut berpartisipasi dalam kelembagaan KIMBis dan secara bertahap SKPD-SKPD tersebut secara aktif melaksanakan kegiatannnya manfaatkan kelembagaan KIMBis.

Demikian juga dengan LSM, tingkat partisipasinya dapat dikatagorikan sebagai tingkat partisipasi konsultatif. Hal ini disebabkan karena LSM yang terlibat di dalam KIMBis adalah LSM lokal setempat, mereka menduga bahwa KIMBis akan membawa bantuan. Padahal partisipasi LSM yang diharapkan adalah partisipasi mandiri, karena LSM dapat memobilisasi berbagai potensi sumberdaya untuk mendorong program kegiatannya dengan memanfaatkan kelembagaan KIMBis.

Pada sisi lain partisipasi masyarakat didalam KIMBis telah mengarah pada partisipasi interaktif. Masyarakat secara individu atau kelompok secara aktif melakukan dialog dengan pengurus KIMBis terkait dengan kegiatan kegitan yang perlu dilakukan dan cara melaksanakannya. Namun masyarakat masih mempertimbangkan untung ruginya mereka menjadi bagian dari kegiatan KIMBis, apalagi KIMBis tidak memberi bantuan uang atau peralatan.

Dalam pelaksanaan kegiatan KIMBis hanya memberi bantuan kepakaran melalui teknologi yang diperkenalkan.Partisipasi masyarakat yang diharapkan dalam KIMBis adalah partisipasi mandiri. Masyarakat secara bertahap dapat mengambil keputusan memanfaatkan kelembagaan KIMBIs untuk memperoleh akses terhadap sumber teknologi, sumber modal dan memperluas jaringan pasar sehingga dapat membangun kemandirian ekonomi mereka.

\section{PENUTUP}

Uraian diatas telah memberi gambaran tentang kelembagaan KIMBis, fungsi dan kendala yang dihadapi dalam pelaksanaan KIMBis. Jika REFINE akan dikembangkan pada masa depan, maka dalam struktur organisasinya pada tingkat 
pusat harus ditugaskan seorang penyelia yang bertanggungjawab pada satu atau dua lokasi. Penyelia tersebut berasal dari eselon 2 lingkup Balitbang KP. Keberadaan penyelia ini sangat penting untuk mendorong partisipasi dari Satuan Kerja pemilik teknologi berpartisipasi mandiri dalam KIMBis.

Selanjutnya ketika KIMBis mencoba mengimplementasikan konsepsi REFINE, maka dalam pelaksanaannya harus dilakukan penyesuaian mempertimbangkan aspek sosial dan manajemen. Oleh sebab itu, untuk membangun REFINEyang dapat mengakomodasi kepentingan berbagai pihak maka terdapat berbagai hal yang harus dipertimbangkan:

a) Fungsi REFINE harus ditingkatkan bukan hanya sebagai penyedia teknologi adaptif lokasi (TAL), tetapi diperluas terkait dengan kebutuhan kehidupan sosial ekonomi masyarakat, menumbuhkan kesempatan kerja, dan pendapatan.

b) Implementasi kegiatan penyebaran IPTEK, pemberdayaan masyarakat dan pengembangan ekonomi masyarakat dalam REFINE harus dilakukan dengan prinsip Economic of Scale.

c) Jaringan kerja yang dibangun harus menganut prinsip interkoneksitas, bukan hanya peneliti - penyuluh. Namun, mencakup juga satuan kerja lingkup PEMDA, dunia usaha (CSR), maupun LSM.Interkoneksitas tersebut untuk menjadikan program REFINE sebagai program bersama.

d) Membekali penyuluh perikanan dengan perkembangan IPTEK terkini, dan memfasilitasi mereka agar dapat dijadikan ujung tombak dalam pelaksanaan kegiatan REFINE dan penyebaran IPTEK.

Kelembagaan KIMBis merupakan kelembagaan dengan dua target. Target pertama adalah untuk menerapkan dan menyebarkan IPTEK. Dan Target kedua terkait dengan membangun kewirausahaan dalam masyarakat dengan memanfaatkan teknologi yang diadopsi serta potensi lingkungan strategis setempat.

Terkait dengan target pertama maka semua stakeholder yang memiliki kegiatan berhubungan dengan teknologi dapat memilih dan memanfaatkan kelembagaan ini untuk melakukan kegiatan adopsi dan penyebaran teknologi. Pemanfaatan KIMBis sebagai wadah penyebaran teknologi bagi pemilik teknologi memiliki berbagai manfaat, proses adopsi teknologi dapat dikawal, kelemahan teknologi dapat segera diketahui. Perlu dicatat pemilik teknologi boleh memanfaatkan kelembagaan lain diluar KIMBis untuk melakukan kegiatan adopsi atau penyebaran teknologi, hal ini berarti pemilik teknologi tersebut tidak dapat memperoleh informasi yang cepat dan tepat dalam proses adopsi teknologi.

Target kedua KIMBis adalah memanfaatkan teknologi yang di adopsi menjadi pendorong perkembangan ekonomi masyarakat. Perkembangan ini dilakukan dengan menumbuhkan kewirausahaan secara secara komunal dengan mengembangkan inovasi pemasaran dengan memanfaatkan potensi lingkungan sekitar KIMBis. Pendekatan inisangat efektifuntukmemperkenalkan produk dan memperluas pengembangan pasar.

\section{DAFTAR PUSTAKA}

Agbamu, J.U. 2000. Agricultural ResearchExtension Linkage Systems: An International Perspective. Agricultural Research \& Extension Network. Network Paper No. 106. 24 halaman.

Aghion, P and P. W. Howit. 1997. Endogeneous Growth Theory. MIT Press. 178 pages.

Anonymous, 2011. Jejaring Penelitian Penuluhan Masyarakat Perikanan (Research Extension Fisheries Community Network - REFINE). Badan Penelitian dan Pengembangan Kelautan dan Perikanan. Jakarta. (Unpublished).

Field, J. 2003. Modal Sosial. Terjemahan Nurhadi. Kreasi Wacana. Fontana, A. 2011. Innovate We Can!. How To Create Value Through Innovation in Your Organization and Society. Jakarta: Cipta Inovasi Sejahtera.

Haryono. 2013. Inovasi Teknologi Pertanian Dalam Pemanfaatan lahan Terlantar. Prosiding Seminar Nasional Pemanfaatan dan Pendayagunaan Lahan Terlantar Menuju implementasi Reformasi Agraria. Eds: DKS. Swastika, K. Suradisastra, B. Hutabarat. Bogor: PSEKP. Halaman $60-72$.

Jhingan, ML. 1999. Ekonomi Pembangunan dan Perencanaan.Penterjemah D. Guritno Cetakan ke 7. Jakarta: PT. Radja Grafindo Persada. 660 halaman. 
Luis, S dan JB, Soesetiyo. 2013. SPEx2 Winner Series: Kiat Ciputa Ubah Krisis Menjadi Berkah. 12 perusahaan yang memiliki kemampuan andal. Kompas 2 Nopember 2013. Halaman 33.

2013a). SPEx2 Winner Series: Menjaga TigaraksaAgarTetap Tumbuh. 12 perusahaan yang memiliki kemampuan andal. Kompas 16 Nopember 2013. Halaman 33.

Pretty, J. 1995. Regenerative Agriculture: Policies and Practice for Sustainable and Self Reliance. London. dalam R. Ramirez. 1995. Participatory Learning and Communication Approaches for Managing Pluralism. http: //www.fao.org/documents/show cdr.asp?url file=/ diakses 9 Mei 2005.

Romer, P.M. 1990. Endogenous Technological Change. Journal of Political Economy.98: 71-102.

1994. The Origin of Endogeneous Growth. Journal of Economic Persfectives. 8 (1): 3-22.

Subejo. 2011. Pembangunan Pertanian Visioner Menuju Kejayaan Bangsa. Dalam The Dancing Leader. Hening - Mengalir Bertindak. Penyunting: J. Susanto. Jakarta: PT. Kompas Media Nusantara.
Syaifullah. 2011. Sejarah Pemikiran Ekonomi. Inovasi, Drama Asia dan Kapitalisme Amerika. (unpublish paper). 60 halaman.

Tjondronegoro, SMP. 2011. Desa: Restropeksi ke-1800 menuju Prospek 2030. Dalam Menuju Desa 2030. Penyunting: A. Satria, E. Rustiadi dan A.M Purnomo. Crestpent Press. Halaman 21 - 45

Qomar, M. K. 2003. Indonesia - An example of effective agricultural - research extention linkages. Former Senior Officer, Agricultural Extension \& Training, FAO/UN Headquarter, Rome. Independent Consultant Based In Maryland, USA. 25 pages.

Zuhal. 2013. Gelombang Ekonomi Inovasi. Kesiapan Indonesia Berselancar di Era Ekonomi Baru. Jakarta: Penerbit Gramedia Pustaka Utama. 278 halaman.

Zulham, A. 2012. KIMBis dari Konsep Menjadi Pelopor Penyebaran IPTEK. Jakarta: Balai Besar Penelitian Sosial Ekonomi Kelautan dan Perikanan. 142 halaman. 